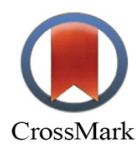

\title{
Post-infectious Irritable Bowel Syndrome: A Narrative Review
}

\author{
Anahita Sadeghi ${ }^{1}$, Mohammad Biglari ${ }^{2}$, Siavosh Nasseri Moghaddam ${ }^{1, *}$
}

1. Digestive Disease Research Institute, Shariati Hospital, Tehran University of Medical Sciences, Tehran, Iran

2. Department of Internal Medicine, Shariati Hospital, Tehran University of Medical Sciences, Tehran, Iran

\section{* Corresponding Author:} Siavosh Nasseri Moghaddam, MD Digestive Disease Research Institute, Shariati Hospital, North Kargar Ave., Tehran, Iran Postal code: 41448-95655 Tel: + 982182415300 Fax: +982182415400 Email: sianasseri@yahoo.com

Received: 02 Jan. 2019 Accepted: 22 May 2019

\section{ABSTRACT}

The Irritable bowel syndrome (IBS) is a functional disorder of alimentary system, which may be caused by infectious gastroenteritis determined as post infectious irritable bowel syndrome (PI-IBS). The prevalence of PI-IBS is reported to be $4-36 \%$ in patients with infectious gastroenteritis. The exact mechanism leading to PI-IBS is not fully understood and some factors pertaining to infectious agent and host response may have a role. Rome IV diagnostic criteria provided new definition for PI-IBS. Though it is now considered a well-defined functional disorder of gastrointestinal system, no specific treatment is yet available for PI-IBS. This article reviews the latest issues on these heading about PI-IBS.

\section{KEYWORDS:}

Irritable Bowel Syndrome, Infectious gastroenteritis, Prevalence

Please cite this paper as:

Sadeghi A, Biglari M, Nasseri Moghaddam S. Post-infectious Irritable Bowel Syndrome: A Narrative Review. Middle East J Dig Dis 2019;11:69-75. doi:10.15171/mejdd.2019.130.

\section{INTRODUCTION}

The Irritable bowel syndrome (IBS) is a functional disorder of alimentary system, which is recently considered as an erroneous gut-brain interaction. ${ }^{1}$ It is a very common diagnosis in gastroenterology practice affecting up to $22 \%$ of general population. ${ }^{2,3}$ IBS symptoms are quite variable and troublesome for patients with a great impact on their quality of life, while there is seldom any abnormalities in the structure of gastrointestinal tract or in the laboratory results. ${ }^{4}$ The vague pathophysiology of IBS has now been more elucidated including mucosal irritability, intestinal dysmotility, and dysbiosis in intestinal microbiome as well as psychosocial factors. ${ }^{5}$

Despite the ambiguous and indolent development of IBS symptoms, $6-17 \%$ of these patients attribute onset of their symptoms to a recent gastrointestinal infection. ${ }^{6,7}$ This so called post-infectious IBS (PI-IBS) represents the persistence of symptoms like diarrhea and abdominal discomfort well after resolution of the culprit infection, ${ }^{8-10}$ which is confirmed in a systematic review that showed up to 6-fold increased risk of PI-IBS after GI infections. ${ }^{11}$

PI-IBS has some similar features with diarrhea dominant IBS cases, though distinct pathophysiologic alterations are recognized in the former. Various factors such as genetic predisposition, psychologic 
background, host defense and behavior of infecting pathogens determine the clinical history and outcome of patients with PI-IBS. It is likely that exposure to infectious organism results in immunologic and inflammatory reactions sustaining IBS symptoms. ${ }^{12}$

Understanding basic mechanisms in PI-IBS may be helpful in clarifying other forms of IBS. This article will review epidemiology, pathophysiology and risk factors as well as symptoms, diagnosis and management of PI-IBS.

\section{Epidemiology}

Records about PI-IBS date back to the Second World War with numerous cases of abdominal discomfort happening in British troops. ${ }^{13}$ Later in 1962, a published case series of so-called 'irritable colon syndrome' described some of them as "post dysenteric irritable bowel syndrome". ${ }^{14}$ Hence, many articles have reported new onset IBS symptoms developing 6-18 months after an infectious episode of gastroenteritis. ${ }^{15-17}$

The prevalence of PI-IBS is reported to be $4-36 \%$ in patients with infectious gastroenteritis. ${ }^{18}$ Considering the high frequency of GI infections and the possibility of these patients not remembering minor or remote infections, it is postulated that the prevalence must be higher. In a large nationwide case control study in United Kingdom, the incidence of IBS was 11.9 times higher in patients with previous infection than uninfected controls (relative risk, $\mathrm{RR}=$ 11.9 [95\% confidence interval [CI], 6.7-21]). ${ }^{19}$

PI-IBS is more prevalent after bacterial than viral infections. ${ }^{20}$ Most common bacteria are Campylobacter, Shigella, E. coli and Salmonella. Recent studies reported cases of PI-IBS after Clostridium dificile infection or even Vibrio species. ${ }^{21-23}$ Amebic GI infection followed by symptoms suggestive of IBS were also reported. ${ }^{24}$

\section{Pathophysiologic Changes}

Patients with PI-IBS show some changes in their gastrointestinal tract that are different from sporadic IBS cases. Inflammation and mucosal injury is a significant response observed in patients with previous infection (e.g. Campylobacter jejuni) which is reported in a study confirming presence of increased number of macrophages and $\mathrm{T}$ lymphocytes in serial intestinal biopsies. ${ }^{25}$ Elevated IL-6 serum levels are evident in IBS patients, as a systematic review reported. ${ }^{26}$ Increased IL-1 expression in rectal samples of PI-IBS patients is another evidence for the pathophysiologic role of inflammation in developing PI-IBS. ${ }^{27-29}$

Altered intestinal permeability leading to submucosal exposure to foreign antigens may also facilitate inflammation due to troubled sensation or motility in gastrointestinal tract. A study managed to show increased intestinal permeability by using lactulose-mannitol excretion ratio. ${ }^{28}$ Similar result was reported in another study but longer follow-up revealed that these changes might resolve in remote futures but not in PI-IBS patients. ${ }^{25}$

Serotonin and enterochromaffin cells have a great role in maintaining healthy gastrointestinal function. Alterations in serotonin production and metabolism have also been noted in PI-IBS patients, ${ }^{25,30}$ though increased serum serotonin level is also observed in some sporadic IBS patients. ${ }^{31}$

\section{Microbiota}

Infectious diarrheal episodes are connected with significant loss of symbiotic bacteria in gastrointestinal lumen. The consequence is transformation of microbial signature due to lack of inhibiting products such as fatty acids. The mentioned proposition is well confirmed in animal studies. ${ }^{32-34}$ Reports of bacterial overgrowth in IBS patients are mostly relied on breath hydrogen tests with high rate of false positive results. ${ }^{18}$

PI-IBS patients have dysbiosis, yet with different scheme from patients with sporadic IBS. ${ }^{35}$ Predisposition to gastrointestinal infections is also related to gut's microbial structure. For example, Bacteroides load is lower in patients who acquire traveler's diarrhea and PI-IBS risk is also lower in these patients. ${ }^{29,36}$ Figure 1 shows the proposed mechanism of dysbiosis by Barbara et al. ${ }^{20}$

\section{Genetic Factors}

Data regarding genetic risk factors for PI-IBS is 


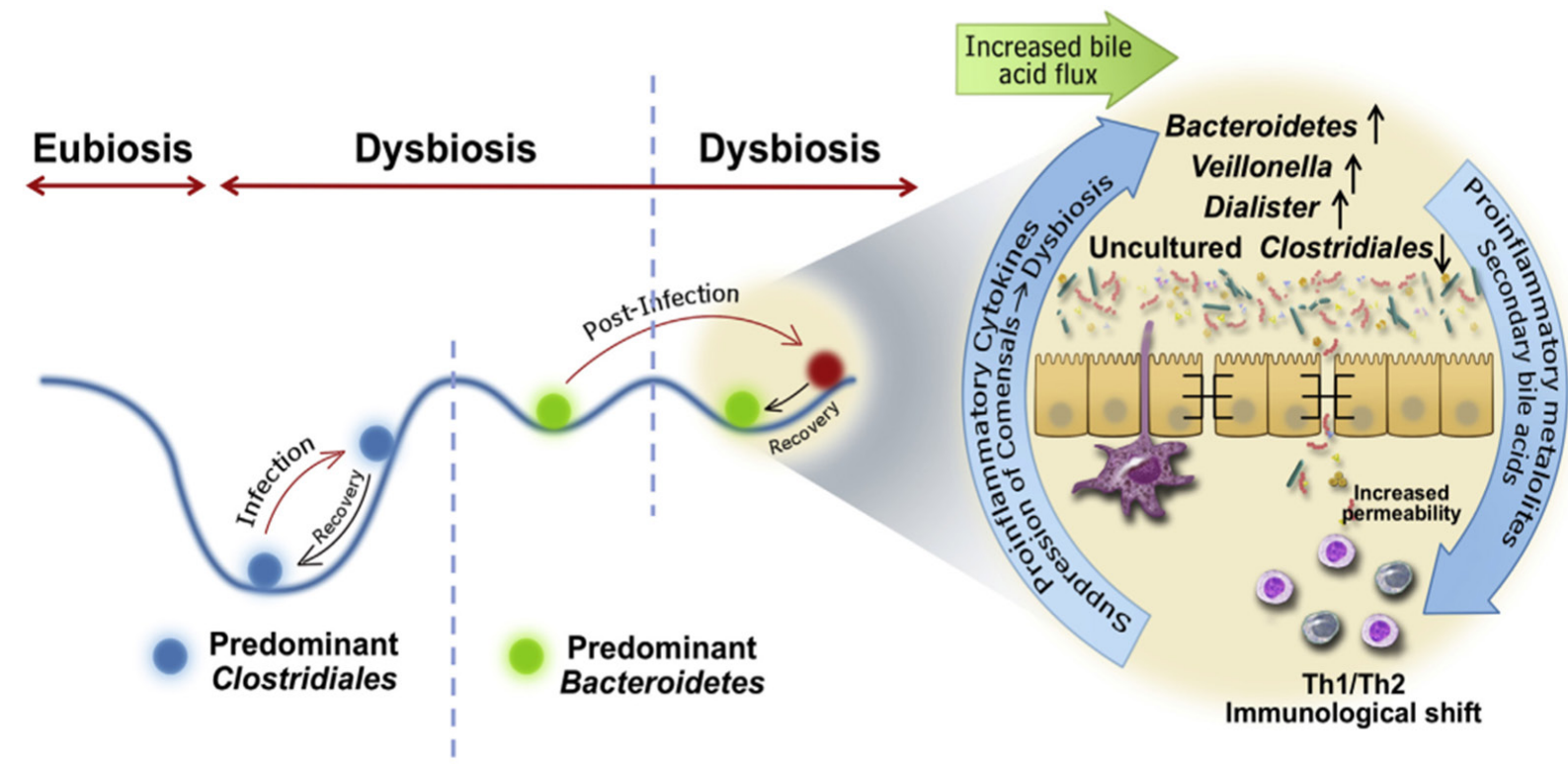

Fig.1: Role of infection-associated shifts in microbiota in PI-IBS. A host with a Clostridiales predominant microbiota type is likely to remain in the eubiosis state after infection, whereas, presence of a Bacteroides predominant community may predispose to development of long-term dysbiosis upon infection. Adapted from Barbara et al..$^{20}$

limited. Although evidence show that genetics may have a role in development of PI-IBS, no confirmed genes are identified. Previous studies revealed the likely role of gene polymorphism resulting in high levels of TNF- $\alpha$ for development of post infectious IBS and lower expression of IL-10 in these patients compared to controls. ${ }^{37,38}$

One of the best researches studying genetic predisposition to PI-IBS was held at Walkerton after an outbreak of infectious gastroenteritis. This study could find an association between toll-like receptor 9, (TLR9), IL-6 and CDH1 gene variants with PIIBS. Although this relationship was not confirmed after considering total number of single nucleotide polymorphisms, it was independent from known clinical risk factors. ${ }^{39}$ More powerful studies are required to elucidate the role of genetic variants in PI-IBS.

\section{Mucosal abnormalities}

Introduction of pathogenic bacteria into the gastrointestinal lumen causes structural and or functional alterations. This may also induce epithelial and enterocyte injury due to toxin exposure. Mucosal hallmarks of inflammation such as edema, erythema or trivial hemorrhage might also be apparent in the acute phase. ${ }^{31,40}$ More virulent pathogens are associated with more inflammatory damage including lymphocyte infiltration and villous reduction.

Previous studies revealed that post infectious changes are almost temporary and resolves within 2 weeks to 3 months, though they may be above normal limits even in longer periods. Immunohistochemical assessments with synaptophysin also showed elevated level of this cell marker in PI-IBS patients. ${ }^{25}$

\section{Host factors}

Older age ( $>60$ years) was described to be protective against developing symptoms of PI-IBS $(\mathrm{RR}=0.36 ; 95 \% \mathrm{CI} 0.3-0.9)$ which is believed to be due to alterations in immunologic response in this age group. ${ }^{19}$ Other studies though revealed no effect for age. ${ }^{41}$

Most of studies to date are congruent that female sex is an established risk factor for developing PIIBS. Relative risk reported are in range of 1.5 to 3 . It is evident from larger studies such as Walkerton study that there might be some confounding factors for this association. ${ }^{39,42,43}$ 
Recurrent abdominal pain, on average, at least 1 day/week in the last 3 months, associated with two or more of the following criteria:

- Related to defecation

- Associated with a change in frequency of stool

- Associated with a change in form (appearance) of stool.

* Criteria fulfilled for the last 3 months with symptom onset at least 6 months before diagnosis.

Adapted from Lacey et al. ${ }^{47}$

Table 2: Diagnostic Criteria for Post-infection Irritable Bowel Syndrome (Based on Rome IV)

1. Recurrent abdominal pain, on average, at least 1 day per week in the last 3 months, with symptom onset at least 6 months before diagnosis, associated with two of the following:

a) defecation

b) a change in frequency of stool

c) a change in form (appearance) of stool

2. Symptom development immediately after resolution of acute infectious gastroenteritis

3. Infectious gastroenteritis defined by positive stool culture in a symptomatic individual or presence of two of the following acute symptoms

(when stool culture not available) $^{\mathrm{a}}$ :

a) fever

b) vomiting

c) diarrhea

4. Should not meet criteria for IBS before onset of acute illness ${ }^{b}$

a A recollection of the precise date of onset of IBS symptoms can also be suggestive of PI-IBS.

b Some patients may experience irregular bowel movements before onset of acute illness (but not associated with the frequent pain characteristic of IBS) that can still be defined as developing PI-IBS.

Adapted from Barbara et al. ${ }^{20}$

It seems that greater prevalence of psychologic disorders in women may induce this effect. However, Moss-Morris et al. showed that female gender is an independent factor for PI-IBS with RR of 2.36 (95\% CI, 1.23 - 3.98).41 This study also showed a RR of 1.82 (95\% CI, 1.05 - 1.22) for anxiety and there is a body of evidence for association of psychologic problems with IBS in general. ${ }^{18,43,44}$

\section{Clinical Features}

\section{Diagnosis}

Although there is several symptom-based IBS diagnostic criteria, the diagnosis of IBS is still challenging due to several reasons. ${ }^{45}$ The Manning symptoms-based criteria, the first global IBS diagnostic criteria was proposed in $1978 .{ }^{46}$ Rome IV as the last diagnostic criteria defines IBS as an abdominal pain that is associated with defecation or a change in bowel habit (table 1). ${ }^{47}$

There is no validated definition of PI-IBS. The new diagnostic criteria defined PI-IBS as new onset of IBS after an episode of acute gastroenteritis in individuals who did not have IBS previously ${ }^{20}$ (table 2). Overall, PI-IBS patients have greater stool frequency and looser stools compared to spo- radic IBS. ${ }^{48}$ The frequency of PI-IBS phenotypes is reported as mixed IBS (IBS-M) as the most common PI-IBS phenotype (46\%), diarrhea predominant IBS (IBS-D) (40\%) and constipation predominant IBS (IBS-C) (15\%). ${ }^{49}$

The diagnostic approach for patients with PI-IBS proposed recently has emphasis on excluding alarm signs, obtaining stool culture and limited testing such as complete blood count, $\mathrm{C}$ reactive protein (CRP). ${ }^{20}$ The most common differential diagnoses are acute acquired hypolactasia following gastroenteritis, bile acid malabsorption, inflammatory bowel disease (IBD) and lymphocytic colitis. ${ }^{50-52}$

\section{Management}

To date, there is no specific practice guideline or treatment strategies for PI-IBS. Meanwhile, patient education and providing reassurance is the key element in dealing with these patients. It is evident that troublesome and disturbing symptoms in PI-IBS patients still need to be addressed accordingly.

Different drug classes can be used for treating PI-IBS similar to patients with IBS in general. Opiates provide transit time increase with reduction in secretions and may help IBS-D like symptoms. ${ }^{53}$ 
Controlling pain and tenesmus is of great importance in all IBS phenotypes, hence we may use antispasmodics as well as tricyclic antidepressant with accurate patient selection since these drugs might have unpleasant side effects..$^{54,55}$

As discussed earlier, serotonin (5-HT) has a potential role in pathophysiology of IBS. 5-HT3 agonists are well studies in IBS-D patients with favorable results ${ }^{56}$ while 5-HT4 agonists such as prucalopride are beneficial in managing constipation. ${ }^{57}$ After an episode of gastroenteritis, bile acid malabsorption may ensue. It is confirmed that cholestyramine can alleviate symptoms in PI-IBS patients especially with diarrhea. ${ }^{58,59}$

Though it is shown that antibiotics or probiotics may have a role in controlling symptoms in other functional gastrointestinal disorders (e.g. bacterial overgrowth), ${ }^{60-63}$ their value for treatment of PI-IBS is still not accepted and more well designed researches are needed in this area.

\section{ETHICAL APPROVAL}

There is nothing to be declared.

\section{CONFLICT OF INTEREST}

The authors declare no conflict of interest related to this work.

\section{REFERENCES}

1. Drossman D. Rome IV: functional gastrointestinal disordersdisorders of gut-brain interaction. In: Drossman D, ed. 2016.

2. Singh P, Agnihotri A, Pathak MK, Shirazi A, Tiwari RP, Sreenivas V, et al. Psychiatric, somatic and other functional gastrointestinal disorders in patients with irritable bowel syndrome at a tertiary care center. J Neurogastroenterol Motil 2012;18:324-31. doi:10.5056/jnm.2012.18.3.324.

3. Makharia GK, Verma AK, Amarchand R, Goswami A, Singh P, Agnihotri A, et al. Prevalence of irritable bowel syndrome: a community based study from Northern India. J Neurogastroenterol Motil 2011;17:82-7. doi:10.5056/ jnm.2011.17.1.82.

4. Jamali R, Biglari M. The Comparison of WHOQOLBREF with Disease Specific Heath Related Quality of Life Questionnaire in Irritable Bowel Syndrome. Acta Med Iran 2015;53:717-24.

5. Mayer EA, Savidge T, Shulman RJ. Brain-Gut Microbiome Interactions and Functional Bowel Disorders. Gastroenterology 2014;146:1500-12. doi:10.1053/j.gastro.2014.02.037.
6. Longstreth GF, Hawkey CJ, Mayer EA, Jones RH, Naesdal J, Wilson IK, et al. Characteristics of patients with irritable bowel syndrome recruited from three sources: implications for clinical trials. Aliment Pharmacol Ther 2001;15:959-64. doi:10.1046/j.1365-2036.2001.01010.x.

7. Yarandi SS, Nasseri-Moghaddam S, Mostajabi P, Malekzadeh R. Overlapping gastroesophageal reflux disease and irritable bowel syndrome: increased dysfunctional symptoms. World J Gastroenterol 2010;16:1232-8. doi:10.3748/wjg.v16.i9.1232.

8. Kim HS, Kim MS, Ji SW, Park H. [The development of irritable bowel syndrome after Shigella infection: 3 year follow-up study]. Korean J Gastroenterol 2006;47:300-30.

9. Marshall JK, Thabane M, Borgaonkar MR, James C. Postinfectious irritable bowel syndrome after a foodborne outbreak of acute gastroenteritis attributed to a viral pathogen. Clin Gastroenterol Hepatol 2007;5:457-60. doi:10.1016/j.cgh.2006.11.025.

10. Okhuysen PC, Jiang ZD, Carlin L, Forbes C, DuPont HL. Post-diarrhea chronic intestinal symptoms and irritable bowel syndrome in North American travelers to Mexico. Am J Gastroenterol 2004;99:1774-8. doi:10.1111/j.15720241.2004.30435.x.

11. Thabane M, Kottachchi DT, Marshall JK. Systematic review and meta-analysis: The incidence and prognosis of postinfectious irritable bowel syndrome. Aliment Pharmacol Ther 2007;26:535-44. doi:10.1111/j.1365-2036.2007.03399.x.

12. Thabane M, Marshall JK. Post-infectious irritable bowel syndrome. World J Gastroenterol 2009;15:3591-6. doi:10.3748/wjg.15.3591.

13. Stewart GT. Post-dysenteric colitis. Br Med J 1950;i:4059. doi:10.1136/bmj.1.4650.405.

14. Rodríguez LA, Ruigómez A. Increased risk of irritable bowel syndrome after bacterial gastroenteritis: cohort study. $B M J$ 1999;318:565-6. doi:10.1136/bmj.318.7183.565.

15. Ruigómez A, García Rodríguez LA, Panés J. Risk of irritable bowel syndrome after an episode of bacterial gastroenteritis in general practice: influence of comorbidities.Clin Gastroenterol Hepatol 2007;5:465-9. doi:10.1016/j.cgh.2007.02.008.

16. Soyturk M, Akpinar H, Gurler O, Pozio E, Sari I, Akar S, et al. Irritable bowel syndrome in persons who acquired trichinellosis. Am J Gastroenterol 2007;102:1064-9. doi:10.1111/j.1572-0241.2007.01084.x.

17. Piche T, Vanbiervliet G, Pipau FG, Dainese R, Hébuterne $\mathrm{X}$, Rampal $\mathrm{P}$, et al. Low risk of irritable bowel syndrome after Clostridium diffcile infection. Can J Gastroenterol 2007;21:727-31

18. Spiller R, Garsed K. Postinfectious irritable bowel syndrome. Gastroenterology 2009;136:1979-88. doi:10.1053/j. gastro.2009.02.074.

19. Neal KR, Hebden J, Spiller R. Prevalence of gastrointestinal symptoms six months after bacterial gastroenteritis and risk factors for development of the irritable bowel syndrome: postal survey of patients. BMJ 1997;314:77982. doi:10.1136/bmj.314.7083.779. 
20. Barbara G, Grover M, Bercik P, Corsetti M, Ghoshal UC, Ohman L, et al. Rome Foundation Working Team Report on Post-Infection Irritable Bowel Syndrome. Gastroenterology 2019;156:46-58. doi:10.1053/j.gastro.2018.07.011.

21. Wadhwa A, Al Nahhas MF, Dierkhising RA, Patel R, Kashyap P, Pardi DS, et al. High risk of post-infectious irritable bowel syndrome in patients with Clostridium difficile infection. Aliment Pharmacol Ther 2016;44:576-82. doi:10.1111/apt.13737.

22. Gutierrez RL, Riddle MS, Porter CK. Increased risk of functional gastrointestinal sequelae after Clostridium difficile infection among active duty United States military personnel (1998-2010). Gastroenterology 2015;149:1408-14. doi:10.1053/j.gastro.2015.07.059.

23. Rahman M, Goshal U, Sultana S, Kibria MG, Sultana N, Khan ZA, et al. Long-term gastrointestinal consequences are frequent following sporadic acute infectious diarrhea in a tropical country: A prospective cohort study. $\mathbf{A m ~} \boldsymbol{J}$ Gastroenterol 2018;113:1363-75. doi:10.1038/s41395018-0208-3.

24. Anand AC, Reddy PS, Saiprasad GS, Kher SK. Does non-dysenteric intestinal amoebiasis exist? Lancet 1997;349:89-92. doi:10.1016/S0140-6736(96)06121-1.

25. Spiller RC, Jenkins D, Thornley JP, Hebden JM, Wright $\mathrm{T}$, Skinner M, et al. Increased rectal mucosal enteroendocrine cells, T lymphocytes, and increased gut permeability following acute Campylobacter enteritis and in postdysenteric irritable bowel syndrome. Gut 2000;47:804-11. doi:10.1136/gut.47.6.804.

26. Bashashati M, Moradi M, Sarosiek I. Interleukin-6 in irritable bowel syndrome: A systematic review and metaanalysis of IL-6 (-G174C) and circulating IL-6 levels. $C y$ tokine 2017;99:132-138. doi:10.1016/j.cyto.2017.08.017.

27. Gwee KA, Collins SM, Read NW, Rajnakova A, Deng Y, Graham JC, et al. Increased rectal mucosal expression of interleukin 1 beta in recently acquired post-infectious irritable bowel syndrome. Gut 2003;52:523-6. doi:10.1136/ gut.52.4.523.

28. Marshall JK, Thabane M, Garg AX, Clark W, Meddings J, Collins SM. Intestinal permeability in patients with irritable bowel syndrome after a waterborne outbreak of acute gastroenteritis in Walkerton, Ontario. Aliment Pharmacol Ther 2004;20:1317-22. doi:10.1111/j.13652036.2004.02284.x.

29. Schwille-Kiuntke J, Mazurak N, Enck P. Systematic review with meta-analysis: post-infectious irritable bowel syndrome after travellers' diarrhoea. Aliment Pharmacol Ther 2015;41:1029-37. doi:10.1111/apt.13199.

30. Kim HS, Lim JH, Park H, Lee SI. Increased immunoendocrine cells in intestinal mucosa of postinfectious irritable bowel syndrome patients 3 years after acute Shigella infection-an observation in a small case control study. Yonsei Med J 2010;51:45-51. doi:10.3349/ymj.2010.51.1.45.

31. Dunlop SP, Coleman NS, Blackshaw E, Perkins AC, Singh G, Marsden CA, et al. Abnormalities of 5-hydroxytryptamine metabolism in irritable bowel syndrome.
Clin Gastroenterol Hepatol 2005;3:349-57. doi:10.1016/ S1542-3565(04)00726-8.

32. Fujita K, Kaku M, Yanagase Y, Ezaki T, Furuse K, Ozawa A, et al. Physicochemical characteristics and flora of diarrhoeal and recovery faeces in children with acute gastroenteritis in Kenya. Ann Trop Paediatr 1990;10:339-45.

33. Lupp C, Robertson ML, Wickham ME, Sekirov I, Champion OL, Gaynor EC, et al. Host-mediated inflammation disrupts the intestinal microbiota and promotes the overgrowth of Enterobacteriaceae. Cell Host Microbe 2007;2:204. doi:10.1016/j.chom.2007.08.002.

34. Pimentel M, Chatterjee S, Chang C, Low K, Song Y, Liu $\mathrm{C}$, et al. A new rat model links two contemporary theories in irritable bowel syndrome. Dig Dis Sci 2007;53:982-9. doi:10.1007/s10620-007-9977-z.

35. Jalanka J, Salonen A, Fuentes S, de Vos WM. Microbial signatures in post-infectious irritable bowel syndrome-toward patient stratification for improved diagnostics and treatment. Gut Microbes 2015;6:364-9. doi:10.1080/194 90976.2015.1096486.

36. Sundin J, Rangel I, Repsilber D, Brummer RJ. Cytokine response after stimulation with key commensal bacteria differ in post-infectious irritable bowel syndrome (PIIBS) patients compared to healthy controls. PLoS One 2015;10:e0134836. doi:10.1371/journal.pone.0134836.

37. van der Veek PP, van den BM, de Kroon YE, Verspaget HW, Masclee AA. Role of tumor necrosis factor-alpha and interleukin-10 gene polymorphisms in irritable bowel syndrome. Am J Gastroenterol 2005;100:2510-6. doi 10.1111/j.1572-0241.2005.00257.x.

38. Gonsalkorale WM, Perrey C, Pravica V, Whorwell PJ, Hutchinson IV. Interleukin 10 genotypes in irritable bowel syndrome: evidence for an inflammatory component? Gut 2003;52:91-3. doi:10.1136/gut.52.1.91.

39. Villani AC, Lemire M, THhabane M, Belisle A, Geneau G, Garg AX, et al. Genetic Risk Factors for PostInfectious Irritable Bowel Syndrome Following a Waterborne Outbreak of Gastroenteritis. Gastroenterology 2010;138:1502-13. doi:10.1053/j.gastro.2009.12.049.

40. Park JH, Rhee PL, Kim G, Lee JH, Kim YH, Kim JJ, et al. Enteroendocrine cell counts correlate with visceral hypersensitivity in patients with diarrhoea-predominant irritable bowel syndrome. Neurogastroenterol Motil 2006;18:53946. doi:10.1111/j.1365-2982.2006.00771.x.

41. Moss-Morris R, Spence M. To "lump" or to "split" the functional somatic syndromes: can infectious and emotional risk factors differentiate between the onset of chronic fatigue syndrome and irritable bowel syndrome? Psychosom Med 2006;68:463-9. doi:10.1097/01. psy.0000221384.07521.05.

42. Dunlop SP, Jenkins D, Neal KR, Spiller RC. Relative importance of enterochromaffin cell hyperplasia, anxiety, and depression in postinfectious IBS. Gastroenterology 2003;125:1651-9. doi:10.1053/j.gastro.2003.09.028.

43. Gwee KA, Leong YL, Graham C, McKendrick MW, Col- 
lins SM, Walters SJ, et al. The role of psychological and biological factors in postinfective gut dysfunction. Gut 1999;44:400-6. doi:10.1136/gut.44.3.400.

44. Drossman DA, McKee DC, Sandler RS, Mitchell CM, Cramer EM, Lowman BC, et al. Psychosocial factors in the irritable bowel syndrome. A multivariate study of patients and nonpatients with irritable bowel syndrome. Gastroenterology 1988;95:701-8.

45. Lacy BE, Patel NK. Rome Criteria and a Diagnostic Approach to Irritable Bowel Syndrome. J Clin Med 2017;6: 99. doi:10.3390/jcm6110099.

46. Manning AP, Thompson WG, Heaton KW, Morris AF. Towards positive diagnosis of the irritable bowel. $\mathrm{Br}$ Med $\mathrm{J}$ 1978;2:653-4. doi:10.1136/bmj.2.6138.653.

47. Lacy BE, Mearin F, Chang L, Chey WD, Lembo AJ, Simren M, et al. Bowel Disorders. Gastroenterology 2016;150:1393-1407. doi:10.1053/j.gastro.2016.02.031.

48. Card T, Enck P, Barbara G, Boeckxstaens GE, Santos J, Azpiroz F ,et al. Post-infectious IBS: Defining its clinical features and prognosis using an internet-based survey. United European Gastroenterol J 2018;6:1245-1253. doi: $10.1177 / 2050640618779923$.

49. Klem F, Wadhwa A, Prokop LJ, Sundt WJ, Farrugia G, Camilleri M, et al. Prevalence, risk factors, and outcomes of irritable bowel syndrome after infectious enteritis: a systematic review and meta-analysis. Gastroenterology 2017;152:1042-54. doi:10.1053/j.gastro.2016.12.039.

50. Parry SD, Barton JR, Welfare MR. Is lactose intolerance implicated in the development of post infectious bowel symptoms in previously asymptomatic people? Eur $J$ Gastroenterol Hepatol 2002;14:1225-30.

51. Perk G, Ackerman Z, Cohen P, Eliakim R. Lymphocytic colitis: a clue to an infectious trigger. Scand J Gastroenterol 1999;34:110-2.

52. Sanders DS, Carter MJ, Hurlstone DP, Pearce A, Ward AM, McAlindon ME, et al. Association of adult coeliac disease with irritable bowel syndrome: a case-control study in patients fulfilling ROME II criteria referred to secondary care. Lancet 2001;358:1504-8. doi:10.1016/ S0140-6736(01)06581-3.

53. Spiller R, Aziz Q, Creed F, Emmanuel A, Houghton L, Hungin P,et al. Guidelines on the irritable bowel syndrome: mechanisms and practical management. Gut 2007;56:1770-98. doi:10.1136/gut.2007.119446.

54. Schoenfeld P. Effcacy of current drug therapies in irritable bowel syndrome: what works and does not work. Gastroenterol Clin North Am 2005;34:319-35. doi:10.1016/j. gtc.2005.02.002.

55. Hovdenak N. Loperamide treatment of the irritable bowel syndrome. Scand J Gastroenterol Suppl 1987;130:81-4.

56. Myren J, Lovland B, Larssen SE, Larsen S. A doubleblind study of the effect of trimipramine in patients with the irritable bowel syndrome. Scand $J$ Gastroenterol 1984;19:835-43.
57. Dizdar V, Gilja OH, Hausken T. Increased visceral sensitivity in Giardia-induced postinfectious irritable bowel syndrome and functional dyspepsia. Effect of the 5HT3-antagonist ondansetron. Neurogastroenterol Motil 2007;19:977-82. doi:10.1111/j.1365-2982.2007.00988.x.

58. Williams AJ, Merrick MV, Eastwood MA. Idiopathic bile acid malabsorption--a review of clinical presentation, diagnosis, and response to treatment. Gut 1991;32:1004-6. doi:10.1136/gut.32.9.1004.

59. Barkun A, Love J, Gould M, Pluta H, Steinhart AH. Bile acid malabsorption in chronic diarrhea: pathophysiology and treatment. Canadian J Gastroenterol Hepatol 2013;27:653-9.

60. Amirimani B, Nikfam S, Albaji M, Vahedi S, NasseriMoghaddam S, Sharafkhah M, et al. Probiotic vs. Placebo in Irritable Bowel Syndrome:A Randomized Controlled Trial. Middle East J Dig Dis 2013;5:98-102.

61. Galatola G, Grosso M, Barlotta A, Ferraris R, Rovera L, Ariano M, et al. Diagnosis of bacterial contamination of the small intestine using the $1 \mathrm{~g}[14 \mathrm{C}]$ xylose breath test in various gastrointestinal diseases. Minerva Gastroenterol Dietol 1991;37:169-75.

62. Nayak AK, Karnad DR, Abraham P, Mistry FP. Metronidazole relieves symptoms in irritable bowel syndrome: the confusion with so-called "chronic amebiasis". Indian J Gastroenterol 1997;16:137-9.

63. Pimentel M, Chow EJ, Lin HC. Eradication of small intestinal bacterial overgrowth reduces symptoms of irritable bowel syndrome. Am J Gastroenerol 2000;95:3503-6. doi: 10.1111/j.1572-0241.2000.03368.x. 